\section{Foliculitis necrotizante herpética}

\author{
CRISTINA BELLO C. ${ }^{1}$, SUSANA BURGOS C. ${ }^{2}$, \\ CONSUELO CÁRDENAS D. ${ }^{1}$, SERGIO GONZÁLEZ B. ${ }^{3}$

\section{Necrotizing herpes folliculitis. Report of one case}

Herpes folliculitis is a rare manifestation of herpes virus infection. It usually represents a diagnostic challenge, due to the absence of characteristic skin manifestations such as vesicles or pustules. The reported cases are mainly associated with varicella zoster virus (VZV) and less commonly with herpes simplex viruses (HSV-1 y HSV-2). We report a 51-year-old male with a relapsing non-Hodgkin Lymphoma under chemotherapy, with history of extensive follicular lesions lasting one month. The pathologic study of the lesions was consistent with necrotizing herpes folliculitis. The patient was treated with Valacyclovir, achieving remission of the lesions. The appearance of folliculitis, especially in an immunocompromised patient, should raise the suspicion of herpes virus infection. Polymerase chain reaction may help to elucidate the diagnosis when pathologic findings are non-specific.

(Rev Med Chile 2012; 140: 1589-1592).

Key words: Folliculitis; Herpes virus 5 human; Varicella-zoster virus.

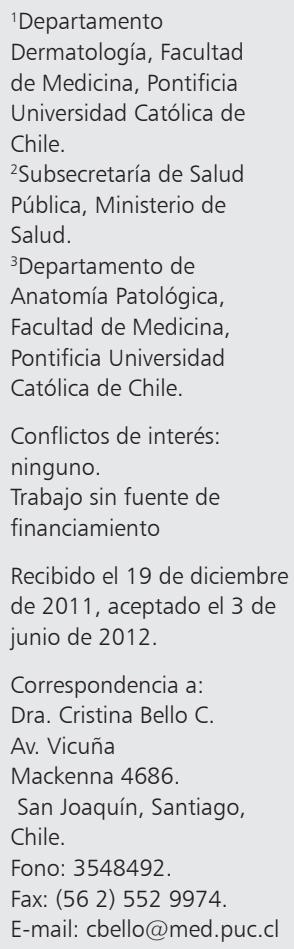

L as infecciones cutáneas por virus de la familia herpes no siempre se presentan de manera típica, por lo que muchas veces pueden ser subdiagnosticadas al no estar presentes los signos clásicos como vesículas y pústulas. El diagnóstico temprano de estas infecciones es crucial para un tratamiento adecuado, por lo que se deben conocer las diferentes manifestaciones clínicas con las que estas infecciones se pueden manifestar ${ }^{1}$. Debe tenerse en cuenta que dentro del espectro de manifestaciones clínicas de las infecciones por virus herpes se encuentra la foliculitis. Esto adquiere mayor relevancia en pacientes inmunosuprimidos, en los que el cuadro puede ser más severo, desarrollando extensa necrosis de los folículos².

La microscopía óptica convencional es un examen que se utiliza rutinariamente para confirmar la infección por virus herpes, pero a veces, los signos clásicos, como las células epiteliales multinucleadas, no se pueden encontrar en la muestra. La RPC permitiría establecer el diagnóstico de las infecciones por virus del herpes, pero el método aún no está disponible en gran parte del mundo, donde el diagnóstico se realiza sólo en base a la morfología, tanto clínica como histopatológica ${ }^{1}$. Presentamos el caso de un paciente inmunosuprimido a quien se le diagnosticó una foliculitis necrotizante herpética, basados en el cuadro clínico y en los hallazgos histopatológicos característicos que describe la literatura ${ }^{2}$.

\section{Caso clínico}

Paciente de sexo masculino de 51 años con antecedente de linfoma no-Hodgkin diagnosticado 2 años antes. El manejo inicial de esta patología incluyó una combinación de radio y quimioterapia y posteriormente un trasplante autólogo de médula ósea con mala respuesta. Evolucionó con recidiva y compromiso esplénico por lo que se inició nuevamente quimioterapia. Se solicitó evaluación a Dermatología por cuadro de un mes de evolución caracterizado por pápulas foliculares extensas, algunas con centro necrótico, asintomáticas, en cuero cabelludo y extremidades (Figuras 1 y 2). Al momento de la consulta se encontraba en su tercer ciclo de terapia combinada EPOCH (etopósido, prednisona, vincristina, ciclofosfamida y doxorrubicina). 


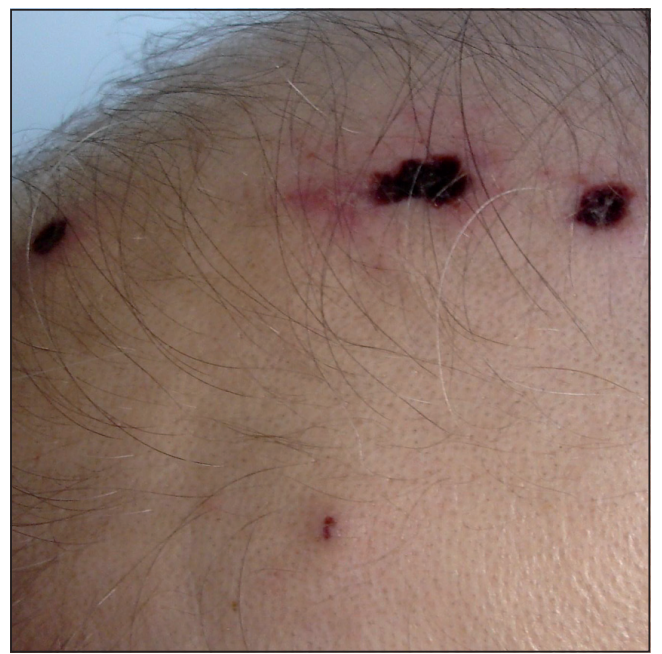

Figura 1. Pápulas foliculares con centro necrótico en cuero cabelludo.

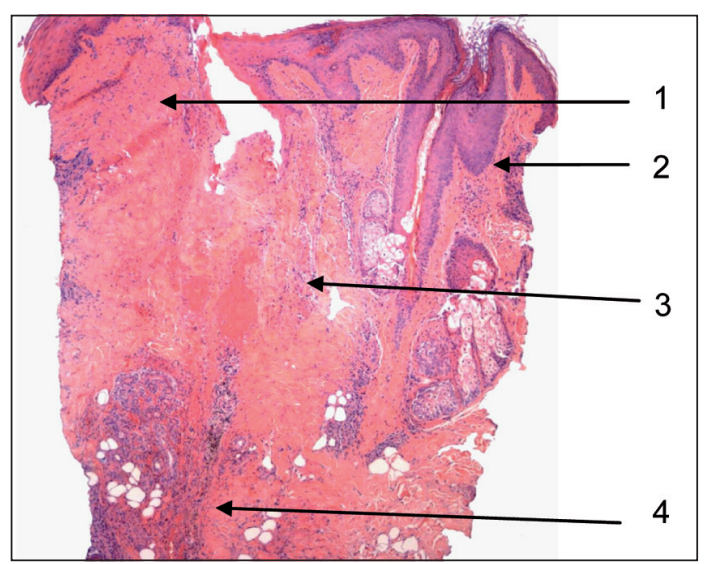

Figura 3. HE 20x. 1) Hemorragia. 2) Folículo conservado. 3) Necrosis del folículo. 4) Exudado Neutrofílico.

El estudio histopatológico reveló un infiltrado inflamatorio predominantemente linfocítico y neutrofílico, perivascular, superficial y profundo e intersticial con leucocitoclasia, necrosis fibrinoide, microtrombos y extravasación de glóbulos rojos. Presentaba extensa necrosis de folículos pilosos con exudado fibrinoleucocitario y queratinocitos mono y multinucleados con inclusiones virales de tipo herpético (Figura 3 y 4 ). Los hallazgos clínicos e histopatológicos descritos fueron compatibles con foliculitis necrotizante herpética. El paciente fue tratado con valaciclovir oral $1 \mathrm{~g}$ cada $8 \mathrm{~h}$ por 7 días con remisión de las lesiones cutáneas.

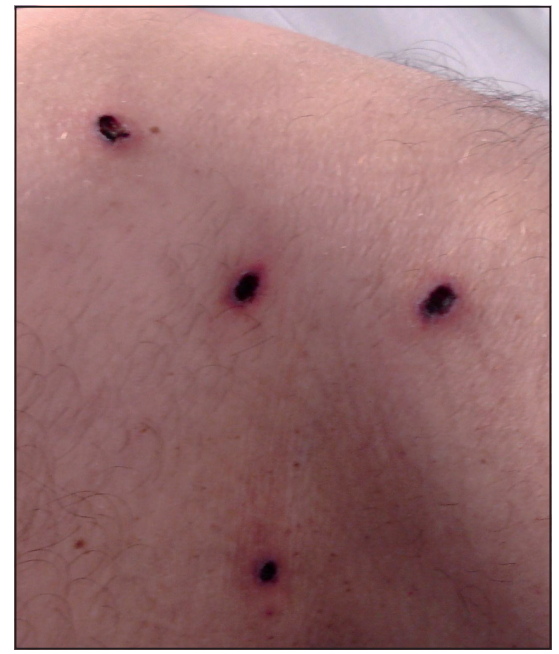

Figura 2. Pápulas foliculares con centro necrótico en extremidades.

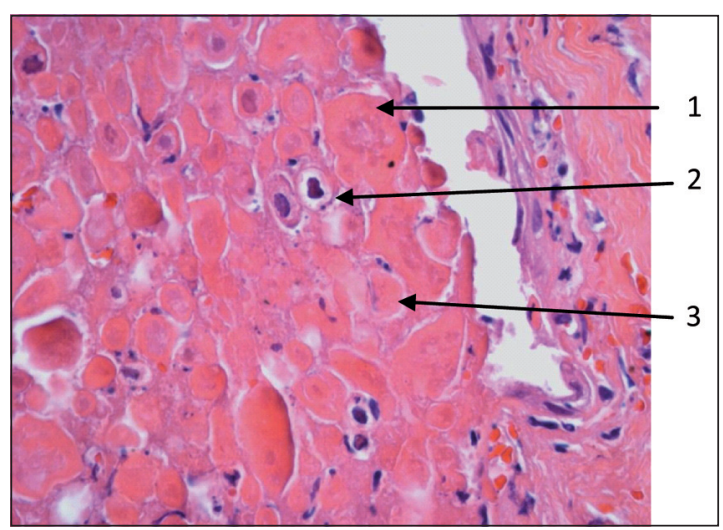

Figura 4. HE 400x. 1) Queratinocitos mono y multinucleados. 2) Inclusiones virales de tipo herpético. 3) Necrosis de queratinocitos foliculares.

\section{Discusión}

En la población general son frecuentes las infecciones por virus herpes ${ }^{3}$. La seroprevalencia del virus varicela zoster (VVZ) según un estudio europeo alcanza la mayor incidencia entre los 7 y los 10 años, con hallazgos serológicos positivos en más de $96 \%$ de la población sobre 12 años ${ }^{4}$. En un estudio multicéntrico realizado en Brasil en pacientes de entre 1 y 40 años, se obtuvo una seroprevalencia global de $85,4 \%$, valor que aumenta en forma directamente proporcional a la edad, alcanzando $94,5 \%$ entre los 31 y 40 años $^{5}$. A nivel 
nacional hay menos datos, pero se estima que $90 \%$ de la población ha adquirido la infección antes de los 10 años de edad ${ }^{6}$. La seroprevalencia de virus herpes simplex reportada en menores de 20 años es de $31 \%$ y $0,5 \%$ para los tipos 1 y 2 respectivamente (VHS-1 y VHS-2) ${ }^{7}$, valores que aumentan en población adulta ${ }^{8}$. Según un estudio norteamericano, la seroprevalencia de VHS-1 y 2 en la población de entre 14 y 49 años, alcanza valores ajustados de $57,7 \%$ y $17,2 \%$ respectivamente ${ }^{3}$. En Chile la prevalencia de VHS- 1 en adultos es de $90 \%$, siendo levemente mayor en pacientes portadores del virus de inmunodeficiencia adquirida ${ }^{9}$. La seroprevalencia de VHS- 2 es de $43 \%$, sin embargo, este dato fue obtenido en pacientes de centros de enfermedades de transmisión sexual ${ }^{10}$.

La infección por estos virus puede provocar una variedad de manifestaciones mucocutáneas, ya sea como parte de la primoinfección o bien de reactivaciones posteriores. Entre éstas, la foliculitis herpética es un cuadro de rara ocurrencia descrito el año 1972 por Izumi et al. ${ }^{11}$, bajo el nombre de sicosis herpética. Los pacientes reportados presentaban lesiones vesiculares agrupadas en el área de la barba con algunas lesiones satélites en la periferia. El estudio histopatológico mostraba cambios citopáticos de tipo herpético con compromiso folicular y de epidermis adyacente. Desde entonces en la literatura se han reportado en forma aislada casos similares de compromiso folicular de origen viral, con manifestaciones variables e incluso en ciertos casos atípicos, los que requieren de estudio histopatológico para su confirmación ${ }^{12}$.

Los hallazgos clínicos más frecuentes descritos en una serie de 21 casos con compromiso folicular herpético son en primer lugar pápulas y placas eritematosas, seguidas por vesículas o pústulas y finalmente úlceras, las que fueron observadas en sólo un caso ${ }^{2}$. El cuadro es de rápida extensión y no se acompaña de manifestaciones sistémicas ${ }^{12}$. La ausencia de lesiones cutáneas características de la infección por virus herpes es un hecho llamativo de esta enfermedad, ante lo que el estudio histológico adquiere mayor importancia diagnóstica. En el caso de nuestro paciente, nunca presentó lesiones vesiculares ni pustulares y la gran mayoría de las pápulas presentaban centros necróticos. Además las lesiones se presentaron en localización atípica, por lo que se decidió realizar estudios histológicos para orientar el diagnóstico. Aun así, los hallazgos microscópicos de las lesiones pueden incluso carecer de elementos considerados diagnósticos, tales como células epiteliales multinucleadas ${ }^{2}$. La serie previamente nombrada menciona entre los hallazgos más constantes la presencia de un infiltrado inflamatorio linfocítico alrededor de los folículos, extravasación de eritrocitos y necrosis de queratinocitos foliculares, ya sea en forma aislada o en "masa". La presencia de células epiteliales multinucleadas, o englobadas, así como de cambios nucleares de los queratinocitos -característicos de la infección por virus herpes ${ }^{1}$ - se registran en esta serie en forma inconsistente. Cambios de la epidermis se encuentran presentes en sólo parte de las muestras, siendo el más común la presencia de linfocitos en la parte basal del estrato ${ }^{2}$.

Estudios complementarios con RPC permiten establecer o confirmar la presencia del ADN viral en muestras incluidas en parafina, siendo este examen más sensible que el cultivo viral ${ }^{13}$. El virus más frecuentemente aislado en estos pacientes según publicaciones recientes es el VVZ, aunque existe evidencia contradictoria en la literatura ${ }^{2,14}$. El uso de antivirales en el episodio agudo está descrito en algunos $\operatorname{casos}^{12,15}$, sin embargo, no se dispone de evidencia suficiente para evaluar su efectividad.

Es un hecho conocido que el trasplante de órganos, en especial el trasplante alogénico de médula ósea, se asocia a un importante estado de inmunosupresión, siendo la infección por VVZ la primera causa de enfermedad viral en el período tardío post-trasplante ${ }^{16}$. En el caso de trasplante autólogo de médula ósea, también se han reportado casos de infección por VVZ, los que se manifiestan en forma localizada, principalmente en dermatomas torácicos o craneales, durante los primeros seis meses posteriores al procedimiento $^{17}$. Los pacientes con inmunosupresión aguda por quimioterapia, como es el caso de nuestro paciente, por lo general, presentan reactivación del VVZ latente y rara vez infección primaria, mientras que la presentación clínica muco-cutánea de las infecciones por VHS consiste generalmente en aumento de la gravedad de la mucositis producida por la quimioterapia, úlceras intrabucales fuera del borde gingival y gingivitis necrotizante ${ }^{18}$. Si bien la foliculitis necrotizante herpética es un fenómeno de rara ocurrencia, se debe tener en consideración en pacientes inmunosuprimidos que presentan pápulas foliculares y placas eritematosas con úlceras necróticas, aún en ausencia de vesículas o pústulas. En este contexto, podrían plantearse 
como diagnósticos diferenciales algunas infecciones cutáneas por hongos, como la aspergilosis y la cigomicosis cutánea. La primera se presenta generalmente en sitios de catéteres venosos o en zonas de oclusión, inicialmente como pequeñas áreas de celulitis que progresan rápidamente a úlceras necróticas con escaras. La segunda puede tener una presentación muy heterogénea, que varía desde pápulas necróticas, nódulos subcutáneos, celulitis, ampollas a escaras. Su diagnóstico suele ser mediante la identificación de hifas no tabicadas en el tejido infectado ${ }^{18}$.

Presentamos este caso para mostrar la importancia de tener muy presente, como una de las primeras posibilidades diagnósticas, una infección por virus herpes ante los hallazgos clínicos descritos, especialmente en pacientes inmunosuprimidos, para poder iniciar lo antes posible el tratamiento. El diagnóstico podría ser corroborado con un estudio histopatológico, siendo necesario en algunos casos complementar con técnicas moleculares cuando se tiene el acceso a éstas.

\section{Referencias}

1. Böer A, Herder N, Blödorn-Schlicht N, Steinkraus V, Falk TM. Refining criteria for diagnosis of cutaneous infections caused by herpes viruses through correlation of morphology with molecular pathology. Indian J Dermatol Venereol Leprol 2006; 72: 270-5.

2. Böer A, Herder N, Winter K, Falk T. Herpes folliculitis: clinical, histopathological, and molecular pathologic observations. Br J Dermatol 2006; 154: 743-6.

3. Xu F, Sternberg M, Kottiri B, McQuillan G, Lee F, Nahmias A, et al. Trends in Herpes Simplex virus type 1 and type 2 seroprevalence in the United States. JAMA 2006; 296: 964-73.

4. Aebi C, Fischer K, Gorgievski M, Matter L, Mühlemann $\mathrm{K}$. Age-specific seroprevalence to varicella-zoster virus: study in Swiss children and analysis of Euorpean data. Vacccine 2001; 19: 3097-103.

5. Clemens S, Azavedo T, Fonseca J, Cavalcante A, Da Silveira T, Clemens R. Seroepidemiología de la varicela en Brasil. Resultado de un estudio prospectivo transversal. Arch Pedriatr Urug 2001; 72 (4): 303-11.

6. Lagos R, Potin M, Tanaka J. Seroprevalencia de anticuerpos antivaricela zoster en población sana del área Norte de Santiago, 1996. Panamerican Ped Congress
(Abstract). Santiago Chile; April 1998.

7. Tumbäk P, Bergström T, Andersson AS, Nordin P, Krantz I, Löwhagen G. Prevalence of herpes simplex virus antibodies in childhood and adolescence: a cross-sectional study. Scand J Infect Dis 2003; 35: 498-502.

8. Cowan FM, French RS, Mayaud P, Gomal R, Robinson NJ, de Oliveira SA, et al. Seroepidemiological study of herpes simplex virus types 1 and 2 in Brazil, Estonia, India, Morocco, and Sri Lanka. Sex Transm Infect 2009; 79: 286-90.

9. Luchsinger V, Amaranta L, Martínez MJ. Elevada seroprevalencia citomegalovirus, virus herpes simplex tipo 1 y virus Epstein Barr en adultos con virus de la inmunodeficiencia humana. Rev Med Chile 2010; 138: 809-14.

10. Martínez MJ, Navarrete N, Santander E, Garmendia ML, Gubelin W. Seropervalencia de la infección por virus herpes simplex tipo 2 en pacientes atendidos en centros de referencia de ETS de Santiago. Rev Med Chile 2005; 133: 302-6.

11. Izumi AK, Kim R, Arnold H Jr. Herpetic sycosis: report of two cases. Arch Dermatol 1972; 106: 372-4.

12. Al-Dhafiri S, Molinari R. Herpetic folliculitis. J Cutan Med Surg 2002; 6 (1): 19-22.

13. Thomas A, Smith S, Morgan TM, White WL, Feldman SR. Clinical application of polymerase chain reaction amplification to diagnosis of herpes virus infection. Am J Dermatopathol 1994: 16 (3): 268-74.

14. Walsh N, Boutilier R, Glasgow D, Schaffelburg M. Exclusive involvement of folliculosebaceous units by herpes: a reflection of early herpes zoster. Am J Dermatopathol 2005; 27 (3): 189-94.

15. Foti C, Filotico R, Calvario A, Conserva A, Antelmi A, Angelini G. Relapsing herpes simples-2 folliculitis in the beard area. Eur J Dermatol 2004; 14: 421-3.

16. Koc Y, Millar K, Schenkein D, Griffith J, Akhtar M, DesJardin F, et al. Varicella zoster virus infections following allogenic bone marrow transplantation. Frequency, risk factors and clinical outcome. Biol Blood Marrow Transplant 2000: 6 (1): 44-9.

17. Schuchter LM, Wingard JR, Piantadosi S, Burns WH, Santos GW, Saral R. Herpes zoster infection after autologous bone marrow transplantation. Blood 1989; 74: 1424-27.

18. Kauls L, Blauvelt A. Capítulo 29: Enfermedades dermatológicas en la inmunosupresión aguda y crónica. Wolf K, Goldsmith L, Katz S, Gilchrest B, Paller A, Leffell D. Fitzpatrick, Dermatología en Medicina General. $7^{\text {a }}$ ed. Buenos Aires: Editorial Médica Panamericana; 2009, p. 267-78. 